\title{
The Arabidopsis expansin gene (AtEXPA18) is capable to ameliorate drought stress tolerance in transgenic tobacco plants
}

\section{Alireza Abbasi ( $\sim$ rezabbasi@ut.ac.ir)}

University of Tehran University College of Agriculture and Natural Resources https://orcid.org/00000003-3598-0419

\section{Meysam Malekpour}

University of Tehran University College of Agriculture and Natural Resources

\section{Sajjad Sobhanverdi}

University of Tehran University College of Agriculture and Natural Resources

\section{Research Article}

Keywords: Agrobacterium tumefaciens, AtEXPA18 gene, Expansin, Drought stress, Tobacco

Posted Date: February 23rd, 2021

DOl: https://doi.org/10.21203/rs.3.rs-204710/v1

License: (a) (1) This work is licensed under a Creative Commons Attribution 4.0 International License. Read Full License

Version of Record: A version of this preprint was published at Molecular Biology Reports on July 29th, 2021. See the published version at https://doi.org/10.1007/s11033-021-06589-2. 


\section{Abstract}

Expansins are cell wall proteins that, due to changes in $\mathrm{pH}$, causing the expansion of the cell walls. In this study, a previously gene construct designed based on a root-specific gene, AtEXPA18, was utilized to assess its potential roles on different morphological, physiological, and cellular levels of generated transgenic tobacco plants in response to moderate and severe drought stress. AtEXPA18 gene was successfully transferred to the tobacco plants through an agrobacterium-mediate transformation system. Upon obtaining the second generation, tobacco transgenic plants were confirmed by conventional polymerase chain reaction (PCR) technique alongside reverse transcription PCR (RT-PCR) using specific primers. Under drought stress, the transgenic lines showed remarkable growth and significantly improved based on morphological traits such as height and stem diameter, leaf area, leaf number, root dry weight, and Abscisic acid (ABA) levels of leaves compared control plants. As a result, the Cytokinin content of transgenic plants has increased under severe stress levels. Notably, the area's expansion for abaxial epidermal cells under the microscope confirmed in transgene cells compared with the -transgene cells. These results, altogether, could support the AtEXPA18 gene implication in cell expansion and improving tolerance capacity of transgenic crops under drought stress.

\section{Introduction}

Throughout the world, nearly all plant species, at least for a short period, are encountered with at least one biotic or abiotic stress. Among them, drought or water deficit stress is assumed to be one of the significant harmful factors, as it can negatively affect crop production of crops worldwide (Li et al. 2015). The plant cellular machinery routinely makes various morphological, physiological, biochemical, and genetic responses, as subsequent, to drought stress. In this way, most of these responses could independently/cooperatively help the plant body system minimize the scale of deleterious consequences of stress. In other words, some plant genotypes, even from single species, may exhibit high levels of tolerance domain so-called "tolerant," whereas others have restricted ability to resist so-called "susceptible. " Hence, it is imperative to improve the tolerance domain of a given plant species under stress conditions, for instance, via introducing novel gene(s) to generate transgenic plants with improved tolerance domain and subsequently higher biomass (Jeong et al. 2010).

Among candidate genes to manipulate for improving plant tolerance to abiotic stress, expansins recently have been attracted many researchers (Cosgrove 2015; Marowa et al. 2016). Expansins are a class of cell wall proteins to promote the flexibility of the plant cell wall, mainly through loosening hydrogen bonds between the cellulose microfibrils and matrix polymer (Choi et al. 2008; Sampedro and Cosgrove 2005). These proteins, which firstly discovered in cucumber hypocotyls (McQueen-Mason et al. 1992), usually encoded by a gene superfamily containing four sub-families: including a-expansin (EXPA), $\beta$ expansin(EXPB), expansin-like A (EXLA), and expansin-like B (EXLB) (Cosgrove 2000; Cosgrove 2015; Kende et al. 2004; Marowa et al. 2016). It is currently well-adopted that they contribute to critical response mechanisms against various environmental cues, mainly through the regulation of cell growth and expansion (Cosgrove 2015; Marowa et al. 2016). For instance, under water deficit stress, at least two 
expansin genes were up-regulated at the maize's root elongation zone and help root growth constantly continue at low water potential (Wu et al. 1996; Wu et al. 2001). In another investigation, Xu et al. (2007)identified a heat-inducible expansin gene in Agrostis scabra called AsEXP1 that could be a useful molecular marker for selecting heat-tolerant grass germplasm. Over-expression of the TaEXPB23 gene could enhance the drought resistance in tobacco plants (Li et al. 2011). Gao et al. (2008) demonstrated that the expression and activity of expansin proteins are induced under drought stress in wheat coleoptiles, suggesting the role of these proteins in response to water deficit circumstances (Gao et al. 2008).

Meanwhile, the regulative interaction between expansins and plant hormones has been suggested in cell enlargement, and cell wall changes under stress (Kuluev et al. 2016). In a recent experiment, the association between Indoleacetic acid (IAA) and Abscisic acid (ABA) and expansin genes in bread wheat was investigated under water deficit conditions (Zhao et al. 2012). The results indicated that an increase of ABA content under osmotic stress caused up-regulation of expansin even though this high activity ramped down by raising the $\mathrm{pH}$ of cell walls by decreasing $\mathrm{H} \rrbracket$-ATPase channel activity. On the contrary, the auxin IAA increased these proteins' activity, mainly by inducing acidic $\mathrm{pH}$ in the cell walls (Zhao et al. 2012). Furthermore, an increase of 20-60 fold in the amount of a $\beta$-expansin protein transcript (called Cim1) occurred by the addition of Cytokinin (Cyt) to Cyt-starved soybean suspension cultures (Downes and Crowell 1998). Meanwhile, the exogenous application of Cyt could induce MeEXPA1 gene expression in Melilotus Alba, demonstrating its potential regulatory roles on the expansins expression (Lee et al. 2008).

It is also believed that root hair distension and elongation thereof are often correlated with increased expansin activity, particularly EXPA18 and EXPA7 genes (Cho and Cosgrove 2002; Lin et al. 2011). Therefore, an AtEXPA18 gene from Arabidopsis thaliana was initially cloned and subsequently transformed into tobacco plants (Nicotiana tabacum L.) to improve these plants' tolerance under moderate or severe water deficit stress circumstances.

\section{Materials And Methods}

\section{Plant materials and transformation requirements}

In this study, a high copy number pGEM-T Easy vector (Promega) and an expression vector of pBI121 (Clontech) carrying the kanamycin resistance gene was employed as plasmids of interest. The bacterium Escherichia coli strain DH5a was used to acquire competent cells and maintain the recombinant vector molecule. Tobacco plant leaves were used for inoculation by Agrobacterium tumefaciens strain LBA4404. The oligonucleotide primer sequences utilized for amplification of AtEXPA18 gene were as follows: AtEXP18 FW 5'-GGATCCCAGAGTAAAAATGGATCAAAATTT-3' (the BamH site is underlined) and AtEXP18 RV 5'-GAGCTCTTAGTTAAAATTAGCCTTGCTCTG-3' (the Sacl site is underlined).

\section{Gene cloning and plant transformation}


The gene construct of 35S::AtEXPA18, designed in our previous work (SHAH et al. 2013), supplemented with a root-specific gene called AtEXPA18 were applied and subsequently cloned into the plant expression vector of pBI121 under the control of CaMV 35S promoter and NOS terminator (Fig. 1). In the following, the concise construct was cloned into the Agrobacterium tumefaciens strain LBA4404, the colonies with the recombinant plasmids were selected on the solidified LB medium (Lauria and Bertani) containing 25 $\mu \mathrm{g} / \mathrm{mL}$ kanamycin and $50 \mu \mathrm{g} / \mathrm{mL}$ rifampicin. Then the PCR-validated colonies were used for tobacco leaf disk transformation (Gallois and Marinho 1995).

The initial transgenic plants obtained from regeneration were then selected on Murashige and Skoog (MS) medium containing $50 \mu \mathrm{g} \mathrm{mL}^{-1}$ kanamycin (Kan) and $400 \mu \mathrm{g} \mathrm{mL}^{-1}$ cefotaxime (Sigma). After growing up in a monitored chamber at $20-22{ }^{\circ} \mathrm{C}, 40-60 \%$ relative humidity under a $16 / 8$-h photoperiod at $100-120 \mu \mathrm{molm}^{-2} \mathrm{~s}^{-1}$, the probable transgenic plants were transferred into the soil and grown in a greenhouse under $12 / 12-\mathrm{h}$ light/dark with a full light intensity of $200-300 \mu \mathrm{mol} \mathrm{m} \mathrm{m}^{-2} \mathrm{~s}^{-1}$ at $25 / 22{ }^{\circ} \mathrm{C}$ (day/night). $T_{1}$ generation seeds were separately obtained at the end of $T_{0}$ generation plant growth and were sterilized and germinated on the selective MS medium with $50 \mu \mathrm{g} / \mathrm{mL}$ Kan to determine transgene inheritance and the number of inserted gene copies. The integrated gene's segregation was determined for each line (i.e., five transgenic lines) by counting resistant and susceptible seedlings to Kan after four weeks of growth in Petri dishes. Further experiments were performed on the L2, L4, L5 lines with a single inherited transgene copy (Kuluev et al. 2012).

\section{Drought stress treatments}

In this step, 45-day-old transgenic and control tobacco seedlings were sown in pots containing $1.5 \mathrm{~kg}$ soil in a greenhouse as described above. A $4 \times 3$ factorial experiment (i.e., four genotypes and three levels of water stress) in the form of a completely randomized design (CRD) with three replications was carried out in the greenhouse to impose drought stress on the transgenic plants. The two experiment factors consisted of plant materials (i.e., transgenic lines namely L2, L4, and L5 alongside one non-transgenic tobacco plant, as control), and drought stress treatments at three different levels (i.e., $40 \%, 60 \%$, and 100 $\%$ field capacity (FC) of pots soil). Drought stress treatments were performed on 18-week-old tobacco seedlings with 15-18 leaves and continued 21-day long. The pots were weighed daily and irrigated according to their corresponding FC.

\section{Conventional PCR and qRT-PCR}

Total genomic DNA was isolated from the green leaves of $T_{0}$ and $T_{1}$ transgenic tobacco plants using the CTAB method (Murray \& Thompson, 1980). The AtEXPA18 gene was amplified via PCR with the specific primers under the following amplification conditions: an initial cycle of $10 \mathrm{~min}$ at $94{ }^{\circ} \mathrm{C}$, a 36-repeated cycle of $1.0 \mathrm{~min}$ at $94^{\circ} \mathrm{C}, 1.0 \mathrm{~min}$ at $60^{\circ} \mathrm{C}$, and $2.0 \mathrm{~min}$ at $72{ }^{\circ} \mathrm{C}$ followed by a final extension step at 72 ${ }^{\circ} \mathrm{C}$ for $5 \mathrm{~min}$. The resultant PCR products were separated on a $1.0 \%$ agarose gel and photographed by a gel documentation apparatus. Total RNA was extracted from the frozen tobacco leaves of T1 generation with the Pbiozol ${ }^{\mathrm{TM}}$ reagent and treated with DNase I (RNase-free, Promega) to remove genomic DNA. 
Reverse transcription was performed using the primer oligo (dT)15 and RevertAid ${ }^{\text {TM }}$ M-MulV Reverse Transcriptase (Fermentas) at $42{ }^{\circ} \mathrm{C}$ for 60 min the same before.

\section{Measurement of morphological and physiological features}

Morphological characteristics of the tobacco plants, including stem height $(\mathrm{cm})$, stem diameter $(\mathrm{mm})$, leaf area index $\left(\mathrm{LAl} ; \mathrm{cm}^{2}\right)$, and the number of leaves, were measured before and after drought stress treatment. In this case, the effects of the transgene expression on cell sizes were evaluated by excising the same age leaves from either transgenic or non-transgenic tobacco plants and dividing them into three distinct parts (i.e., basal, middle, and tip). The lower epidermis of leaves was taken and analyzed with an Axiophot microscope (ZEISS, Germany) after staining with Carmine. Subsequently, the photos were taken by a digital camera mounting to the microscope and connected to the computer and analyzed via Digimizer software (version 4.1.1.0). The areas of cells and cellular density (i.e., the number of cells per $\mathrm{mm}^{2}$ ) were calculated according to the following formula (Kuluev et al. 2012):

Cell number $=$ leaf area/cell area mean

Cell density $=$ cell number $/$ leaf area

Simultaneously, the same old leaf samples were separated and transferred into a $-80^{\circ} \mathrm{C}$ freezer for further molecular analyses. Lastly, at the end of the drought stress period, plant roots were elicited from the soil, washed carefully using distilled water, and oven-dried at $70^{\circ} \mathrm{C}$ for $48 \mathrm{~h}$ to measure dry weight.

\section{Determination of plant pigments}

The measurement of total leaf chlorophyll content was conducted according to the method described by (Arnon 1949; Goodwin 1976). In this context, $400 \mathrm{mg}$ of fresh leaves of each sample were carefully fragmented into tiny segments in $80 \%$ acetone. The extracts were individually centrifuged at $8000 \mathrm{~g}$ for 5 $\mathrm{min}$, then the total chlorophyll and carotenoids contents were determined in terms of the absorbance at the wavelengths of 470,645 , and $663 \mathrm{~nm}$ using Shimadzu UV-160 spectrophotometer. The calculation was carried out through the following formulae:

Total chlorophyll content $=\left[20.2\left(\mathrm{OD}_{645}\right)-2.69\left(\mathrm{OD}_{663}\right)\right] * \mathrm{~V} / 1000 * \mathrm{~W}$

Where $\mathrm{V}$ and $\mathrm{W}$ indicate volume of the extract and weight of leaf segments, respectively.

\section{Extraction, purification, and determination of plant hormones}

The extraction and purification of the phytohormones (i.e., ABA and Cyt) from the frozen leaves were performed, as detailed below. Notably, measurement of both phytohormones was conducted only for $L 4$, L5, and wild-types at only two levels of drought stress, including $100 \%$ FC and $40 \%$ FC. 
Measurement of endogenous ABA levels was performed according to the protocol (Li et al. 2010), with some minor modifications. In brief, $\sim 1.5 \mathrm{~g}$ of the frozen tobacco leaves were finely ground using liquid nitrogen in a mortar and pestle, and $10 \mathrm{~mL}$ of $80 \%$ methanol was added together with $0.01 \mathrm{~g}$ of ascorbic acid and $0.01 \mathrm{~g}$ of polyvinyl pyrrolidone (PVP), actually to prevent oxidation reactions over-extraction. The homogenate was stirred overnight at $4{ }^{\circ} \mathrm{C}$, centrifuged at $4000 \mathrm{~g}$ for $15 \mathrm{~min}$, the supernatant was recovered and adjusted to $\mathrm{pH} 8.0$, and centrifuged as before. The whole supernatant was adjusted to $\mathrm{pH}$ 2.5 and added $10 \mathrm{~mL}$ ethyl acetate. Then, the solution with the free ABA in ethyl acetate was collected, allowed to evaporate ethyl acetate, the residue sediment was dissolved in $1.0 \mathrm{~mL}$ solution containing $3 \%$ methanol and $0.1 \mathrm{M}$ acetic acid, and filtered through a $45 \mu \mathrm{m}$ membrane filter. $20 \mu \mathrm{L}$ of the extract was injected and processed by HPLC (Unicam-crystal-200, England) equipped with a reverse phase column $(4.6 \times 250 \mathrm{~mm}$ Diamonsic C18,5 $\mathrm{m})$. It was eluted with a linear gradient of methanol-acetic acid (3-97 $\%$ ), at a flow rate of $4 \mathrm{mLmin}^{-1}$. The detection was run at $260 \mathrm{~nm}$ with a diode array detector.

Measurement of endogenous Cyt levels was also conducted based on the method described by (Hou et al. 2008). The HiQSil C18, $5.0 \mu \mathrm{m}(4.6 \times 250 \mathrm{~mm})$ column was used to evaluate this phytohormone so that $20 \mu \mathrm{L}$ of the extract was injected into the column and processed by HPLC apparatus. Washing solvent (deionized water: methanol (1:1) with $2.0 \%$ formic acid) was used at a $1 \mathrm{ml} / \mathrm{min}$ flow rate. Quantification was prerformed by comparing the peak areas with initial amounts of ABA and BA (99.97 $\%$, Sigma).

\section{Statistical analysis}

The data were statistically analyzed by IBM SPSS software (Multivariate Analyses of General Linear Model), and Duncan's multiple range tests $(P<0.05)$ was used to determine critical values for comparisons between means. Also, the drawing of diagrams was performed by Excel software, 2013.

\section{Results}

\section{Affirmation of Agrobacterium colonies with recombinant plasmids}

All the transgenic agrobacterium-based colonies containing recombinant plasmids were successfully grown in the selective medium (Fig. 2A). Moreover, the full-length AtEXPA18 gene (i.e., 1228 bp) was confirmed through colony PCR technique and extracted plasmids, indicating the presence of gene construct pBI::EXPA18 in the corresponding colonies (Fig. 2B).

\section{S::AtEXPA18 tobacco lines}

The insertion of AtEXPA18 into the tobacco genome was confirmed by PCR technique in five obtained plants at the first generation called $\mathrm{T}_{0}$ tobacco lines (Fig. 3). The mature seeds of transgenic tobacco lines (called $\mathrm{T}_{1}$ ) were successfully germinated at the selective MS medium (see above), actually owing to the 35S::AtEXPA18 construct expressing the kanamycin resistance gene, Neomycin phosphotransferase (nptll), whereas the wild type and non-transgenic tobacco plants were decayed after germination. The 
number of healthy: unhealthy tobacco seedlings illustrated that transgenic lines' germination occurred nearly with 3:1 differentiation, demonstrating the insertion of one copy of the transgene into the plant genome (Fig. 4), albeit transgenic L3 line showed 15:1 differentiation, exceptionally. After 28 days of growth in petri dishes, all the transgenic lines $\left(T_{1}\right)$ and control plants were acclimated to soil conditions, and the results of RT-PCR confirmed the transgene transcription in transgenic tobacco lines, as the expected amplicon size of 789 bp was visualized (Fig. 5).

\section{Effect of water-deficit stress on morphological characteristics}

The morphological measurements, including stem height and diameter of transgenic lines, were significantly higher than those of control plants $(p<0.01)$ under three levels of water deficit stress. Surprisingly, the transgenic L2 line exhibited the highest stem under three water deficit stress levels and the thickest stem only under control condition (Fig. 6A-C). Upon applying drought stress, however, L2 and L4 had the thickest stem. Comparatively, the LAl in all the three transgenic lines of L2, L4, and L5 were quantified with higher values under either normal or water shortage circumstances $(p<0.05 ; \mathrm{Fig} .7 \mathrm{~A})$, which could be due to the "higher numbers of the leaves" of transgenic lines than wild-type. Notably, drought stress could significantly decline the total LAI of both non-transgenic and transgenic plants, but this phenomenon was more remarkable in the former than the latter. Furthermore, like the earlier three morphological criteria, compared to the wild-type, all the three transgenic lines of $L 2$, $L 4$, and $L 5$ produced higher number of leaves either under normal or water scarcity situations $(p<0.05$; Fig. 7B). Similarly, it appears that drought stress is less effective to diminish number of leaves of all the aforesaid three transgenic lines rather than the wild-type tobacco plants ( $p<0.05$; Fig. 7B).

\section{Effect of water-deficit stress on root dry weight}

Because of AtEXPA18 gene activity in plant root, especially elongation (Cho and Cosgrove 2002), the experimental tobacco roots' dry weight were measured. The results demonstrated a significant difference $(p<0.01)$ between transgenic and control tobacco plants. Indeed, all the three transgenic lines of $L 2, L 4$, and L5 produced higher root dry weight than the wild-type either under normal or water insufficiency circumstances $(p<0.05 ; \mathrm{Fig} .7 \mathrm{C})$. It is worth mentioning that all the three transgenic lines of $\mathrm{L} 2$, $L 4$, and L5 followed by wild-type plants could overall yield higher root biomass under severe drought and particularly moderate stress. This capacity could be due to the plant's ability to adapt to the new situations (moderate drought stress), for instance, by employing elongated root systems to acquire more accessible soil moisture at the lower soil depths. However, root biomass of both transgenic and nontransgenic tobacco plants was rarely declined under severe drought stress, which could be due to a decrement in plant performance to persist extreme drought stress significantly (Fig. 7C). Given to results, the root dry weights under moderate (60\% FC) were higher than those calculated for the other stress levels (unlike stem height), demonstrating that the produced dry materials may have been more allocated into the roots than the stems under water deficit conditions. It should be also noted that transgenic plants had more root hairs than controls. 


\section{Effect of water-deficit stress on total leaf chlorophyll content}

Considering ANOVA results, it seems that genotypes $(p \leq 0.05)$ alongside different levels of drought stress $(p \leq 0.05)$ could significantly vary in terms of the chlorophyll content (Table 1). As Fig 7D shows, except for the L4 line, the other two L2 and L5 lines showed lower chlorophyll content than nontransgenic plants under water shortage conditions.

\section{Phytohormones}

\section{ABA and Cyt variations of leaf tissue of experimental tobacco plants under drought stress}

In this study, due to the close correlation between expansin genes and phytohormones, ABA and Cyt hormones were also isolated from upper extended two leaves of $L 4, L 5$, and wild-type tobacco plants under $100 \% \mathrm{FC}$ and $40 \% \mathrm{FC}$, and analyzed then by HPLC apparatus. The results showed that ABA content in transgenic tobacco leaves was significantly $(p<0.01)$ higher than that of control plants at both non-stress and intensive drought stress levels (Table 2). Means comparison investigation revealed that the transgenic $L 4$ line had the highest ABA content of leaf by $88.20 \mathrm{nmol} \mathrm{g}^{-1}$. $\mathrm{FW}^{-1}$ at two drought levels (Fig. 8A). As Fig. 8A shows, an increment in ABA content from $100 \% \mathrm{FC}$ to $40 \% \mathrm{FC}$ in L2, L4, and control lines was $1.67,1.42$, and 2.14 , respectively. Notably, albeit the ratio of $A B A$ content in control lines was higher than $L 2$ and $L 4$, the absolute values of the phytohormone $A B A$ in both transgenic tobacco lines were remarkably higher than that of control, either under $100 \% \mathrm{FC}$ or $40 \% \mathrm{FC}$. Unlike ABA, Cyt variation between transgenic and non-transgenic tobacco leaves wasn't significant (Table 2), but there was a notable point in this phytohormone's content at severe drought stress (40 \% FC; Fig. 8B). Under severe drought stress (40\% FC), a little Cyt enhancement was observed in transgenic tobacco leaves, whereas the control plant leaves demonstrated a decrease of Cyt level compared with $100 \%$ FC (Fig 8B).

\section{Effect of water-deficit stress on cellular levels characteristics}

For investigating the effects of AtEXPA18 transgene expression on the cellular sizes, the areas of lower epidermal cells were calculated using a microscope (Table 3; Fig. 9). The results demonstrated that the average cell area and the leaf area of AtEXPA18-carrying plants were approximately $9 \%$ greater and $25 \%$ larger than those of control plants, respectively. The data also showed that the lower number of cells per unit area of the leaf surface is related to the enlargement of the cells in transgenic plants. In this case, transgenic plants had, on average, 6.02 cells per $1.0 \mathrm{~mm}^{2}$ compared to the non-transgenic plants by 6.61 cells per $1.0 \mathrm{~mm}^{2}$ (Table 1). Therefore, transgenic tobacco plants supplemented with AtEXPA18 possessed extended walls and large partitions, possibly because of its function at cell walls compared with the non-transgenic plants.

\section{Discussion}

Expansins are involved in several biological functions, including plant growth, development, and environmental stress resistance (Choi et al. 2008; Cosgrove 2015; Jones and McQueen-Mason 2004; 
Marowa et al. 2016). In this work, we investigated the effects of AtEXPA18 overexpression to improve drought tolerance by analyzing phenotype and hormone variation of T1 generation of transgenic tobacco lines under drought stress.

In general, the overexpressing of the AtEXPA18 had positive effects on plant organ growth, which were in agreement with the earlier observations (Cho and Cosgrove 2002). Also, under drought stress, transgenic plants had higher biomass than non-transgenic plants, agreeing with (Li et al. 2011). It has been reported that expansins activities occur mostly in young and undifferentiated cells, which normally lead to a growth in the stem length and diameter mainly via further expansion of these cells (Gray-Mitsumune et al. 2008). As it is known, cell division and cell expansion, as two vital events, play a significant role in the conversion of leaf primordium to mature leaf in plants, and after the cell division phase, the leaf mainly grows further through turgor-driven cell expansion, cell wall loosening and de novo synthesis of cell wall components (Gonzalez et al. 2012). Similarly, here, the overexpression of AtEXPA18 in cell expansion phase led to the generation of larger leaves in transgenic tobaccos as compared with the control plants. At the study of Pien et al. (2001), it was similarly indicated that the localized induction of expansin transgene expression on the flanks of tobacco vegetative meristems not only induced the appearance of leaf primordial, but also reiterated the entire process of leaf development and produced phenotypically normal leaves (Pien et al. 2001). Drought stress alters the pattern of assimilates allocation, as in most plants, it changes the biomass allocation pattern in favor of root, so the plant is able to use limited water supply effectively. Plants with the highest drought tolerant have more root weight, longer roots and more root/shoot ratio than susceptible cultivars. Considering that EXPA18 gene expression occurs in roots with high rate and causing root's expansion (Cho and Cosgrove 2002), it was expected that transgenic tobaccos are able to grow more than control plants under stress condition, as the same results were deduced here.

On the other hand, it is clear that ABA level is usually increased in plants during biotic or abiotic stress and plays a key role in plant signal transduction and response to these stresses (Xiong et al. 2002). Here, the results showed that ABA content in transgenic tobacco leaves was significantly higher than that of control plants at both non-stress and severe drought stress levels. Hence, due to changes in ABA content and differences between AtEXPA18 transgenic lines and control plants, there seems to be a close relationship between the $A B A$ hormone and the expression of expansin genes. It has been demonstrated that $A B A$ induces expansin activity, mainly through enhancing expansin expression since the ABA induces cell wall basification via decreasing plasma membrane H+-ATPase activity, which was unfavorable for expansin activity (Zhao et al. 2012). Given the high content of ABA hormone in transgenic tobacco leaves, it could be hypothesized that the increasing amount of AtEXPA18 protein in the cell wall and the dual effects of this hormone on the protein activities disturbed the existing balance between them. As a result, the plant tends to increase its leaf ABA content, especially in guard cells, actually to maintain water under drought conditions.

Even though little information is available regarding the relationship between cytokinin hormone and expansin genes activities, several studies have been confirmed the potential relationships between each 
other. For instance, it has been reported that Cyt regulates a soybean $\beta$-expansin gene expression by a post-transcriptional mechanism (Downes and Crowell 1998). In addition, numerous investigation has been recorded the role of exogenous application of Cyt and related expansin genes (Kuluev et al. 2016; Lee et al. 2008; Li et al. 2014; Lu et al. 2016). Here Cyt content in the leaves of transgenic tobacco was increased already after aggregation of AtEXPA18 protein at cell walls under severe drought stress, suggesting the potential role of expansin to improve this hormone content and subsequently plant tolerance versus drought stress circumstance.

\section{Conclusions}

In conclusion, our results indicated that intensified expression of an expansin gene could positively provoke the growth of different organs of transgenic tobaccos, and subsequently, higher plat biomass could be acquired under water stress conditions. Meanwhile, analysis of plant hormones in transgenic lines confirmed the relationship between them and expansin genes activities, the exact evidence of this matter requires subsequent experiments. Finally, this gene's overexpression could be recommended as a typical growth regulator, mainly to obtain transgenic plants with larger organs and extensive drought tolerance domain.

\section{Declarations}

\section{Acknowledgment}

We kindly appreciated the University of Tehran for providing plant biotechnology lab and greenhouses.

\section{Declaration}

1. All author equally made substantial contributions to the conception or design of the work, analysis, or interpretation of data.

2. All authors approved this version to be published.

3. All materials and data clearly reported and are accessible.

\section{Conflict of interest}

There is no conflict of interest

\section{Founding}

Not applicable

\section{References}

1. Arnon DI (1949) Copper enzymes in isolated chloroplasts. Polyphenoloxidase in Beta vulgaris Plant physiology $24: 1$ 
2. Cho H-T, Cosgrove DJ (2002) Regulation of root hair initiation and expansin gene expression in Arabidopsis. Plant Cell 14:3237-3253

3. Choi D, Kim JH, Lee Y (2008) Expansins in plant development Advances. in Botanical Research 47:47-97

4. Cosgrove DJ (2000) Loosening of plant cell walls by expansins. Nature 407:321-326

5. Cosgrove DJ (2015) Plant expansins: diversity and interactions with plant cell walls. Curr Opin Plant Biol 25:162-172

6. Downes BP, Crowell DN (1998) Cytokinin regulates the expression of a soybean $\beta$-expansin gene by a post-transcriptional mechanism. Plant molecular biology 37:437-444

7. Gallois P, Marinho P (1995) Leaf disk transformation using Agrobacterium tumefaciens-expression of heterologous genes in tobacco. In: Plant gene transfer and expression protocols. Springer, pp 3948

8. Gao Q, Zhao M, Li F, Guo Q, Xing S, Wang W (2008) Expansins and coleoptile elongation in wheat Protoplasma 233:73

9. Gonzalez N, Vanhaeren H, Inzé D (2012) Leaf size control: complex coordination of cell division and expansion. Trends in plant science 17:332-340

10. Goodwin TW (1976) Chemistry and biochemistry of plant pigments. Volumes 1 and 2 Chemistry and biochemistry of plant pigments Volumes 1 and 2

11. Gray-Mitsumune M, Blomquist K, McQueen-Mason S, Teeri TT, Sundberg B, Mellerowicz EJ (2008) Ectopic expression of a wood-abundant expansin PttEXPA1 promotes cell expansion in primary and secondary tissues in aspen. Plant biotechnology journal 6:62-72

12. Hou S, Zhu J, Ding M, Lv G (2008) Simultaneous determination of gibberellic acid, indole-3-acetic acid and abscisic acid in wheat extracts by solid-phase extraction and liquid chromatographyelectrospray. tandem mass spectrometry Talanta 76:798-802

13. Jeong JS et al (2010) Root-specific expression of OsNAC10 improves drought tolerance and grain yield in rice under field drought conditions. Plant physiology 153:185-197

14. Jones L, McQueen-Mason S (2004) A role for expansins in dehydration and rehydration of the resurrection plant Craterostigma plantagineum. FEBS Lett 559:61-65

15. Kende $\mathrm{H}$ et al (2004) Nomenclature for members of the expansin superfamily of genes and proteins. Plant molecular biology 55:311-314

16. Kuluev B, Avalbaev A, Mikhaylova E, Nikonorov Y, Berezhneva Z, Chemeris A (2016) Expression profiles and hormonal regulation of tobacco expansin genes and their involvement in abiotic stress response. Journal of plant physiology 206:1-12

17. Kuluev B, Knyazev A, Lebedev YP, Chemeris A (2012) Morphological and physiological characteristics of transgenic tobacco plants expressing expansin genes: AtEXP10 from Arabidopsis and PnEXPA1 from poplar Russian. J Plant Physiol 59:97-104 
18. Lee A, Giordano W, Hirsch AM (2008) Cytokinin induces expansin gene expression in Melilotus alba Desr. wild-type and the non-nodulating, non-mycorrhizal (Nod-Myc-) mutant Masym3 Plant signaling \& behavior 3:218-223

19. Li AX, Han YY, Wang X, Chen YH, Zhao MR, Zhou S-M, Wang W (2015) Root-specific expression of wheat expansin gene TaEXPB23 enhances root growth and water stress tolerance in tobacco Environmental. and Experimental Botany 110:73-84

20. Li F et al (2011) Drought tolerance through over-expression of the expansin gene TaEXPB23 in transgenic tobacco. Journal of plant physiology 168:960-966

21. Li X-J, Yang M-F, Chen H, Qu L-Q, Chen F, Shen S-H (2010) Abscisic acid pretreatment enhances salt tolerance of rice seedlings: proteomic evidence Biochimica et Biophysica Acta (BBA)-Proteins. and Proteomics 1804:929-940

22. Li X, Zhao J, Walk TC, Liao H (2014) Characterization of soybean $\beta$-expansin genes and their expression responses to symbiosis, nutrient deficiency, and hormone treatment Applied. microbiology biotechnology 98:2805-2817

23. Lin C, Choi H-S, Cho H-T (2011) Root hair-specific EXPANSIN A7 is required for root hair elongation in Arabidopsis. Mol Cells 31:393-397

24. Lu Y, Liu L, Wang X, Han Z, Ouyang B, Zhang J, Li H (2016) Genome-wide identification and expression analysis of the expansin gene family in tomato Molecular. Genetics Genomics 291:597608

25. Marowa P, Ding A, Kong Y (2016) Expansins: roles in plant growth and potential applications in crop improvement. Plant cell reports 35:949-965

26. McQueen-Mason S, Durachko DM, Cosgrove DJ (1992) Two endogenous proteins that induce cell wall extension in plants. Plant Cell 4:1425-1433

27. Pien S, Wyrzykowska J, McQueen-Mason S, Smart C, Fleming A (2001) Local expression of expansin induces the entire process of leaf development and modifies leaf shape Proceedings of the National Academy of Sciences 98:11812-11817

28. Sampedro J, Cosgrove DJ (2005) The expansin superfamily Genome biology 6:242

29. SHAH NBS, ABASSI A, ALIZADE H (2013) Overexpression of AtEXPA18 in Arabidopsis thaliana

30. Wu Y, Sharp RE, Durachko DM, Cosgrove DJ (1996) Growth maintenance of the maize primary root at low water potentials involves increases in cell-wall extension properties, expansin activity, and wall susceptibility to expansins. Plant Physiol 111:765-772

31. Wu Y, Thorne ET, Sharp RE, Cosgrove DJ (2001) Modification of expansin transcript levels in the maize primary root at low water potentials. Plant Physiol 126:1471-1479

32. Xiong L, Schumaker KS, Zhu J-K (2002) Cell signaling during cold, drought, and salt stress The plant cell 14:S165-S183

33. Xu J, Tian J, Belanger FC, Huang B (2007) Identification and characterization of an expansin gene AsEXP1 associated with heat tolerance in C3 Agrostis grass species. J Exp Bot 58:3789-3796 
34. Zhao M-r, Han Y-y, Feng Y-n, Li F, Wang W (2012) Expansins are involved in cell growth mediated by abscisic acid and indole-3-acetic acid under drought stress in wheat. Plant cell reports 31:671-685

\section{Tables}

Table 1. ANOVA results for stem height, stem diameter, LAI, number of leaves, root dry weight, and total chlorophyll content

\begin{tabular}{cccccccc}
\hline SOV & Df $^{\mathrm{b}}$ & $\begin{array}{c}\text { Stem } \\
\text { height }\end{array}$ & $\begin{array}{c}\text { Stem } \\
\text { diameter }\end{array}$ & LAI & $\begin{array}{c}\text { Number of } \\
\text { leaves }\end{array}$ & $\begin{array}{c}\text { Root dry } \\
\text { weight }\end{array}$ & $\begin{array}{c}\text { Total } \\
\text { chlorophyll }\end{array}$ \\
\hline $\begin{array}{c}\text { Genotypes } \\
(\mathrm{G})\end{array}$ & 3 & $105.78^{* *}$ & $0.85^{* *}$ & $5051.23^{*}$ & $29.65^{* *}$ & $0.14^{* *}$ & $55.03^{*}$ \\
$\begin{array}{c}\text { Stress (S) } \\
\text { G } \times \text { S }\end{array}$ & 2 & $30.88^{* *}$ & $0.19^{\mathrm{ns}}$ & $55878.71^{* *}$ & $104.86^{* *}$ & $0.30^{* *}$ & $69.40^{*}$ \\
\hline Error & 24 & 11.83 & 0.08 & 1541.925 & 3.00 & $.010^{\mathrm{ns}}$ & $25.94^{\mathrm{ns}}$ \\
\hline
\end{tabular}

Both * and ** exhibit significant levels at $P \leq 0.05$ and $P \leq 0.01$, respectively, while " $n s^{\prime \prime}$ means "not significant". a: Source of Variation

b: Degree of Freedom

Table 2. ANOVA results for ABA, and Cyt contents

\begin{tabular}{cccc}
\hline SOV $^{\mathrm{a}}$ & Df $^{\mathrm{b}}$ & ABA & Cyt \\
& & & \\
\hline Genotypes (G) & 2 & $2882.47^{* *}$ & $59.46^{\mathrm{ns}}$ \\
Stress (S) & 1 & $2260.16^{* *}$ & $0.57^{\mathrm{ns}}$ \\
\hline G $\times$ S & 2 & $164.00^{\text {ns }}$ & $30.37^{\text {ns }}$ \\
\hline Error & 12 & 48.07 & 23.85
\end{tabular}

Both * and ** exhibit significant levels at $P \leq 0.05$ and $P \leq 0.01$, respectively, while " $n s$ " means "not significant". a: Source of Variation

b: Degree of Freedom

Table 3. The sizes of the lower epidermal leaf cells of the transgenic and control plants under the microscope.

\begin{tabular}{ccccc}
\hline Criteria & Control plants & \multicolumn{3}{c}{ Transgenic plants } \\
\cline { 3 - 5 } & & L2 & L4 & L5 \\
\hline Average cell area $\left({\left.\mu \mathrm{m}^{2}\right)}^{2}\right.$ & $151293 \pm 4927$ & $166223 \pm 6544$ & $164460 \pm 6799$ & $167112 \pm 5346$ \\
Leaf area Index $\left(\mathrm{cm}^{2}\right)$ & 45.6 & 53.9 & 52.3 & 65.0 \\
\hline Total number of cells & 30140.19 & 32426.32 & 31801.05 & 38896.07 \\
\hline The number of cells per $\mathrm{mm}^{2}$ & 6.61 & 6.02 & 6.08 & 5.98 \\
\hline
\end{tabular}




\section{Figures}

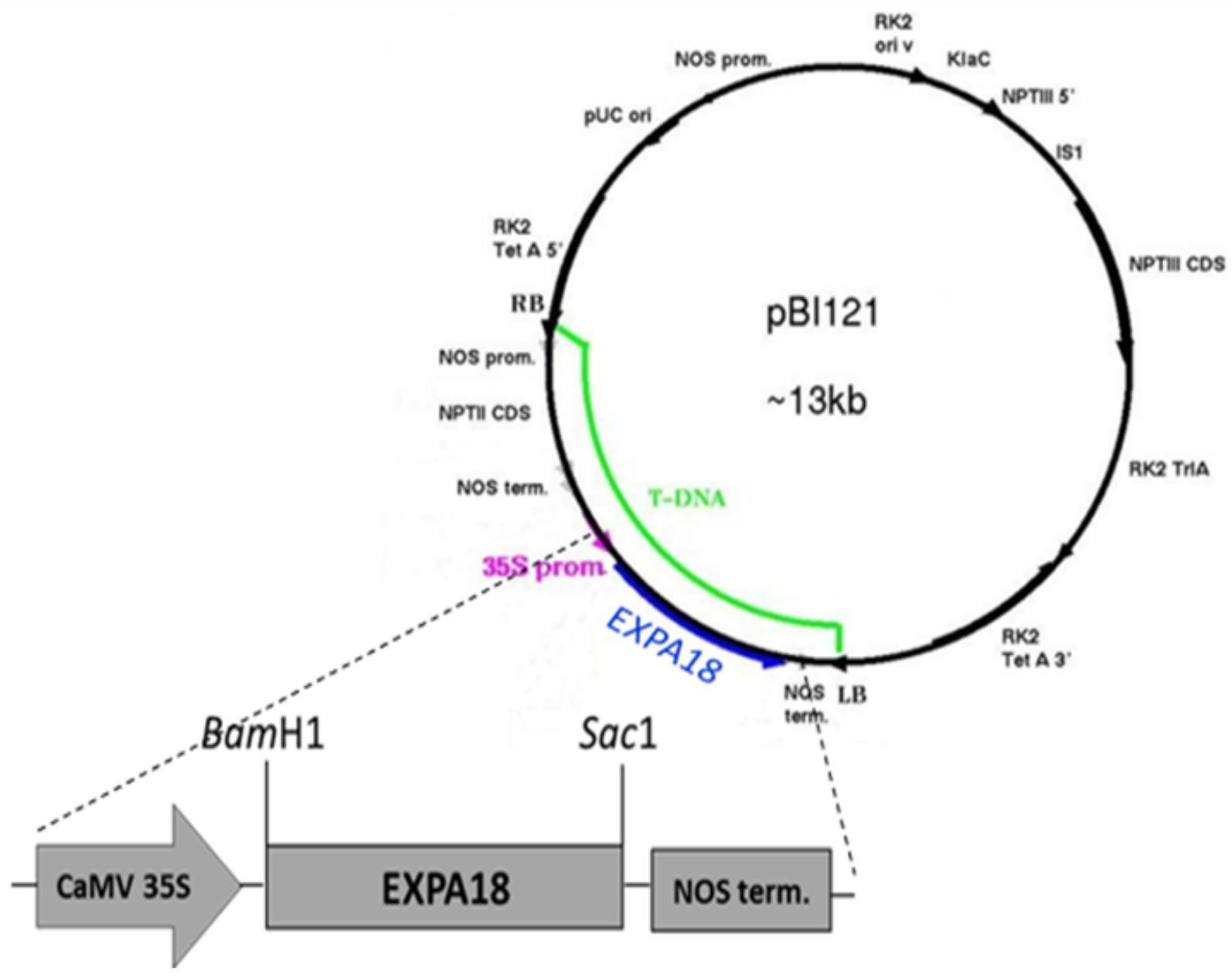

Figure 1

The schematic representation of pBI::AtEXPA18 gene construct utilized in this study.

A

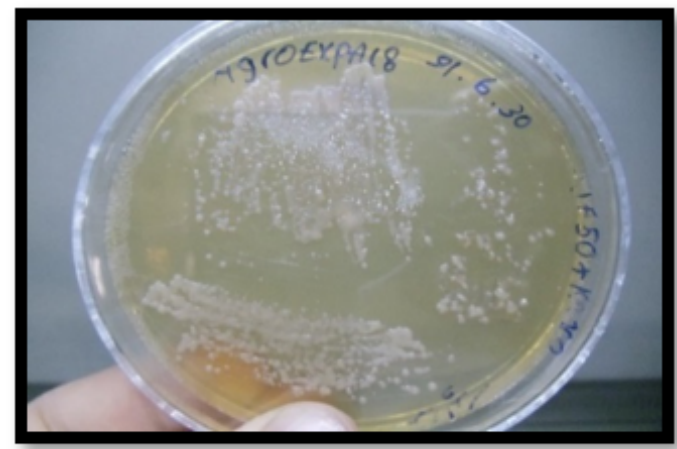

1

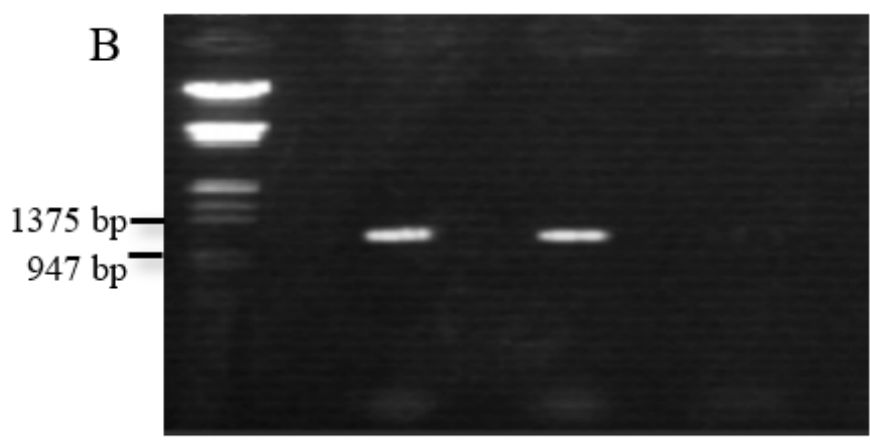

$1228 \mathrm{bp}$

Figure 2 
Confirmation of gene construct pBI::EXPA18 in Agrobacterium. (A) Growth of agrobacterium colonies with recombinant plasmids on solidified LB medium containing kanamycin and rifampicin. (B) PCR products: $1,2,3$, and 4 indicate Molecular weight marker $\lambda /$ EcoRI+HindIII (Qiagen), transgenic agrobacterium colony, recombinant plasmid, and non-transgenic agrobacterium colony, respectively.

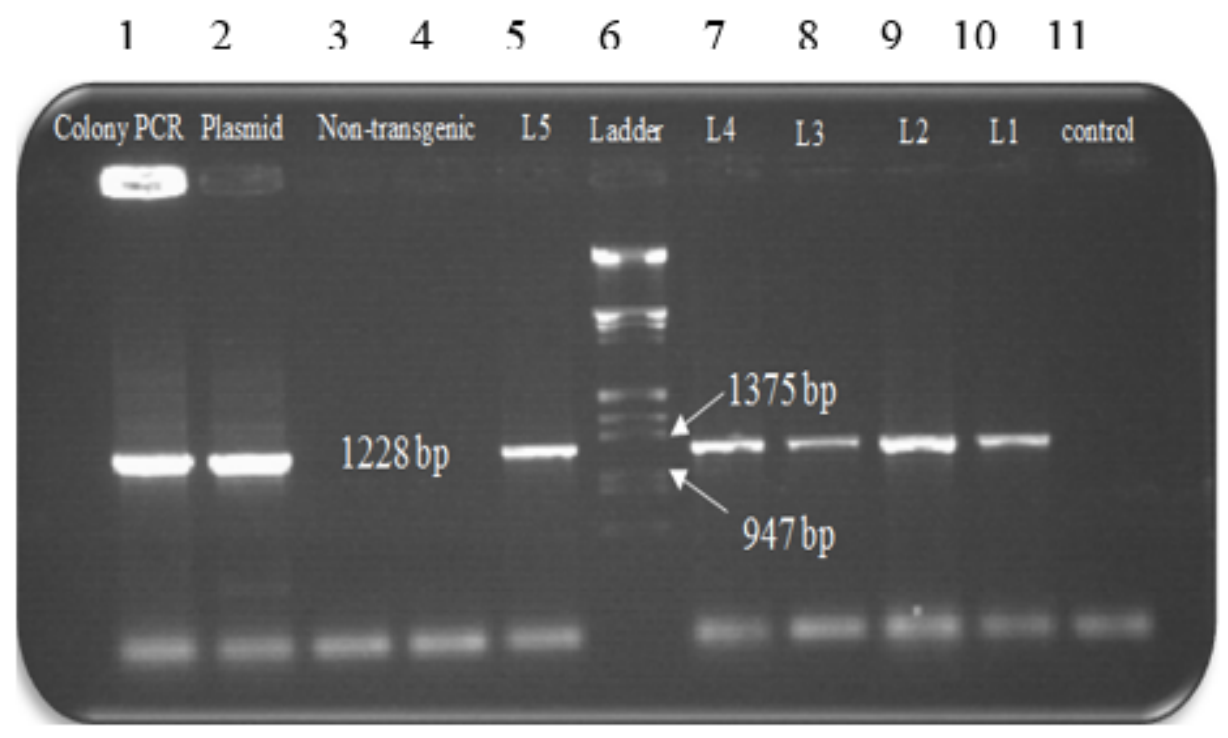

\section{Figure 3}

The results of amplification of the full length AtEXPA18 gene. 1,2) Agrobacterium colony and plasmid PCR (positive control); 3,4 ) Non-transgenic tobacco; $5,7,8,9,10)$ transgenic lines; 6) molecular weight marker ( $\lambda /$ EcoRI+HindIII); 11) control tobacco (negative control).
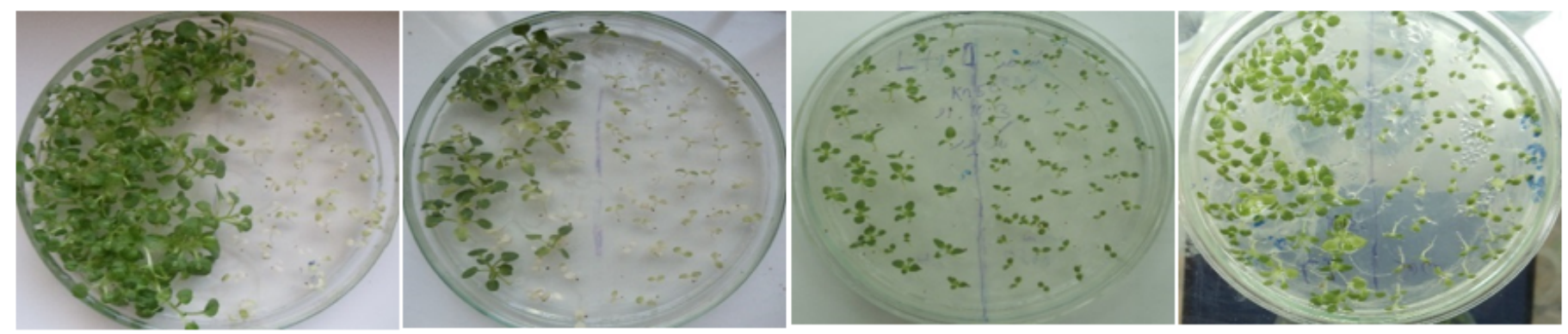

\section{Figure 4}

Germination and growth of transgenic (left side of petri dishes) and wild-type (right side of petri dishes) tobacco seeds in selective medium. 


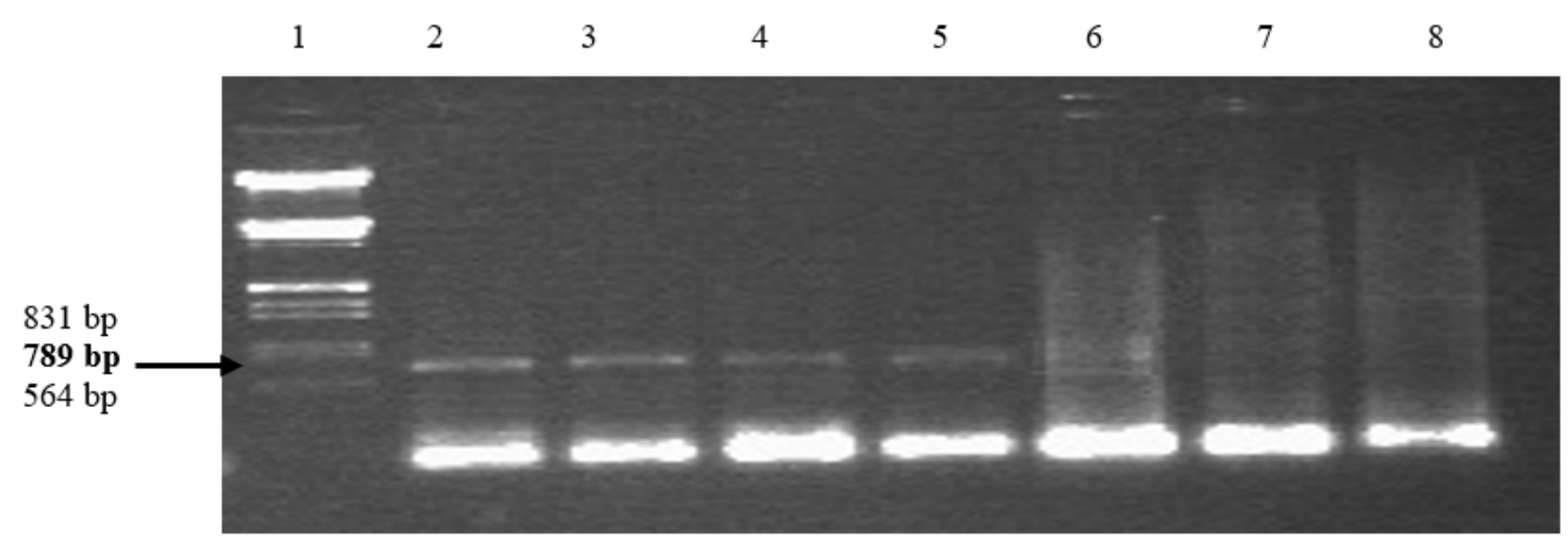

\section{Figure 5}

Electrophoresis of RT-PCR products of AtEXPA18 in the transgenic tobacco plants, the T1 generation. 1) Molecular weight marker ( $\lambda$ / EcoRI+HindIII), 2-6) Transgenic tobacco lines carrying 35S::AtEXPA18 construct (T1 generation) with the expected size of 789 bp, 7) Wild type tobacco and 8) Negative control of PCR.
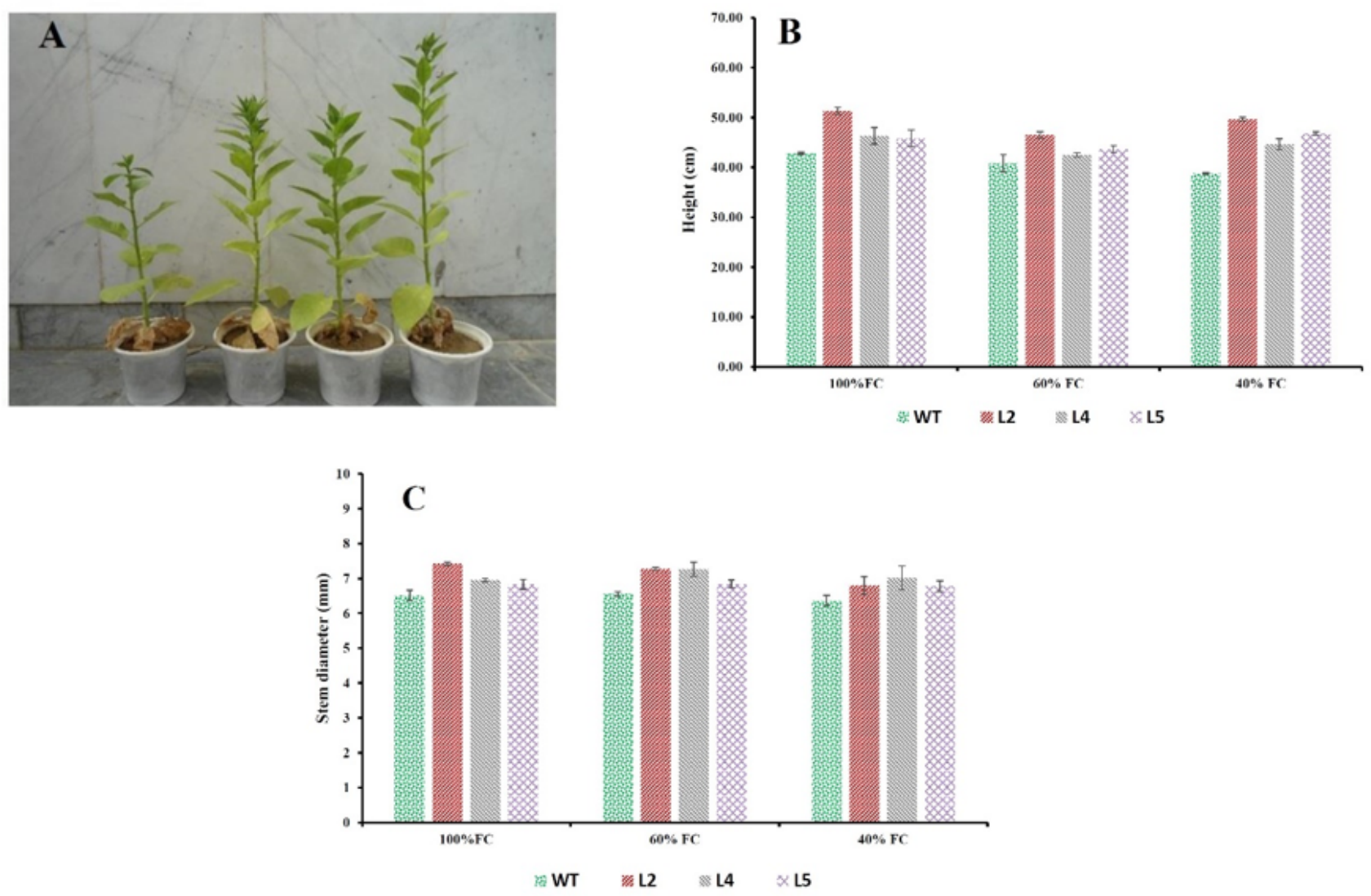

Figure 6 
A) Wild-type, L5, L4, L2 (from left to right); The height (B) and stem diameter (B) of transgenic lines as compared with wild-type tobacco under control and drought stress treatments.
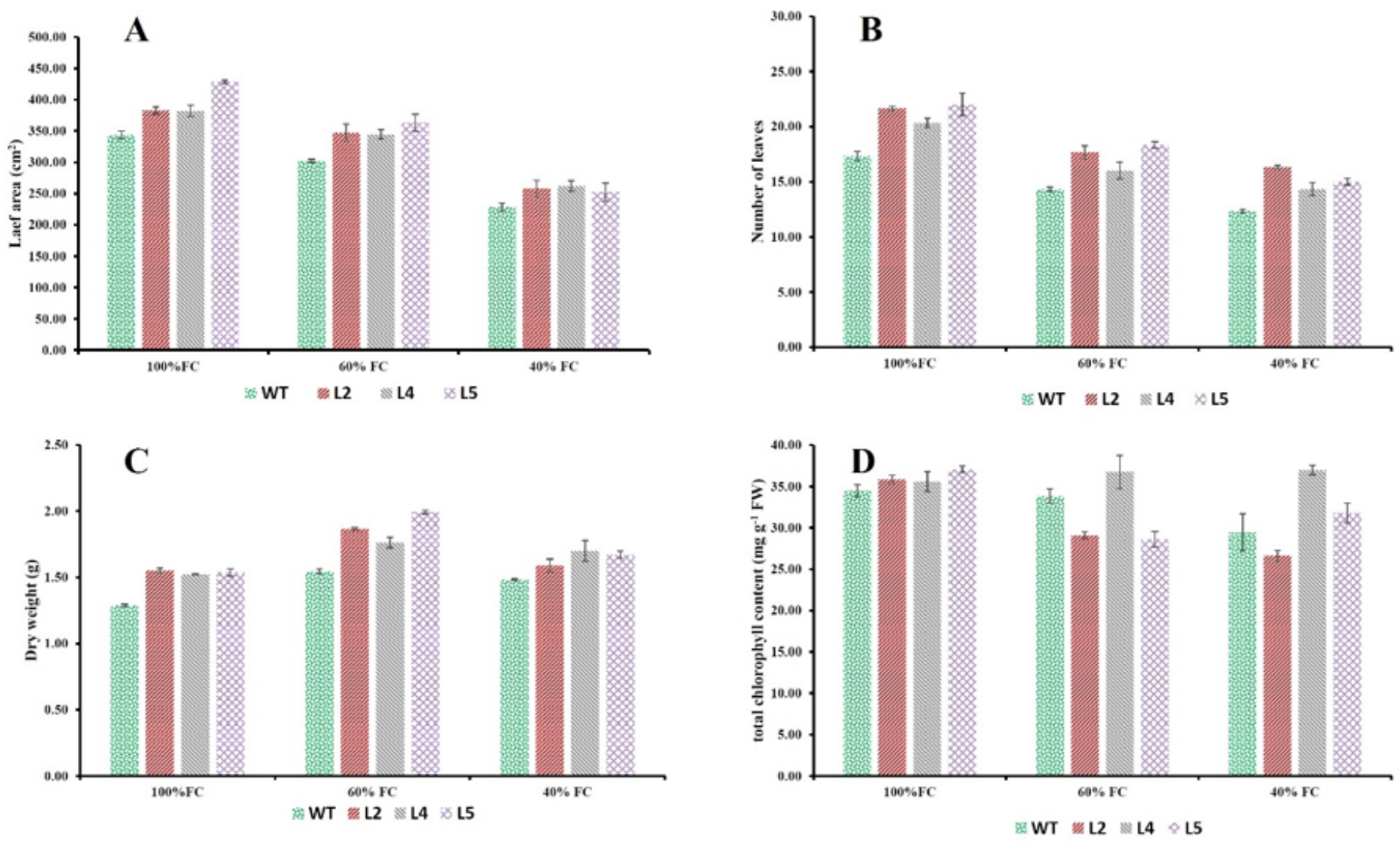

\section{Figure 7}

Leaf area (A), Number of leaves (B), Dry weight (C), and Total chlorophyll content (D) of transgenic lines as compared with wild-type tobacco under control and drought stress treatments.
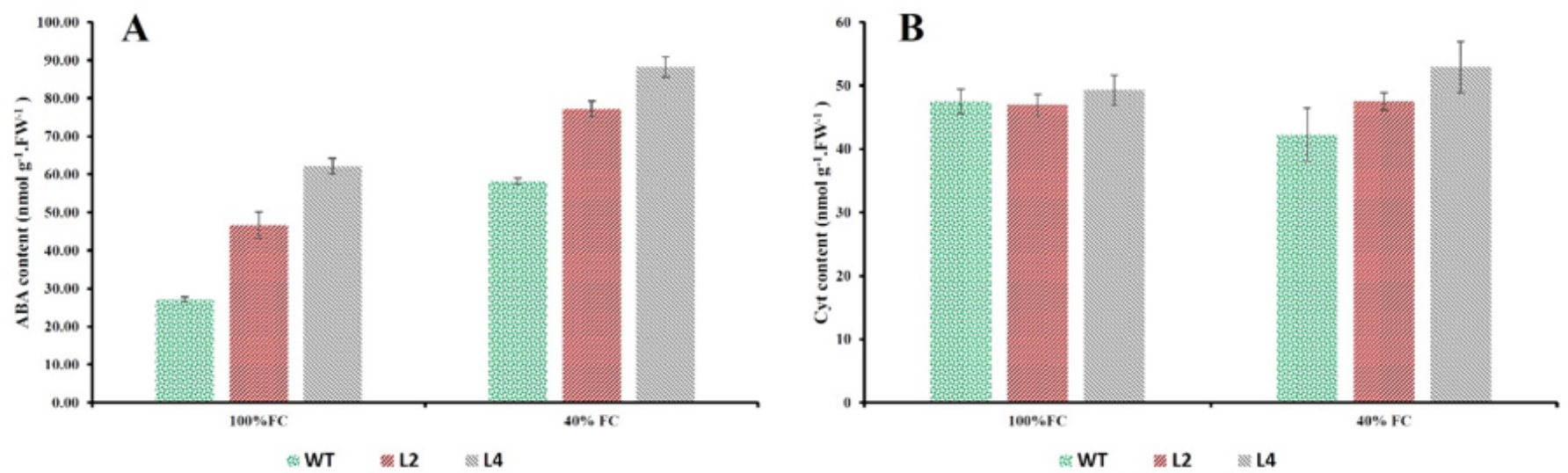

Figure 8

Variations of $A B A(A)$ and Cyt $(B)$ contents of the leaves of transgenic lines as compared with wild-type tobacco plants at two drought stress levels of $100 \%$ and $40 \%$ FC. 

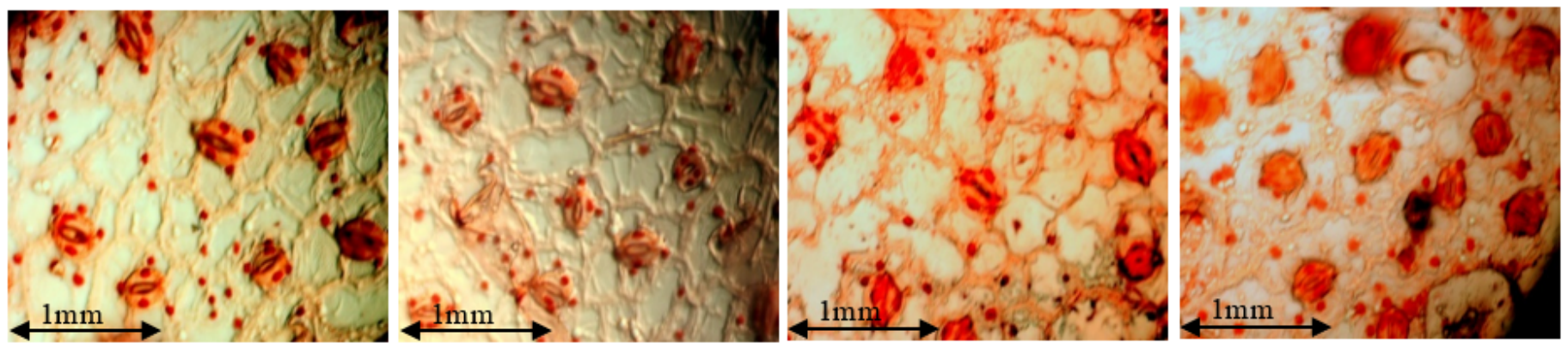

Figure 9

Leaf epidermal cells of the transgenic and control plants under the microscope. From left to right, epidermal cells of L2, L4, L5 and wild type, respectively. AtEXPA18 expressing lines have the greater cell area than control plants. 